\title{
Tocotrienol rich fraction supplementation improved lipid profile and oxidative status in healthy older adults: A randomized controlled study
}

Siok-Fong Chin', Johari Ibahim', Suzana Makpol', Noor Aini Abdul Hamid', Azian Abdul Latiff², Zaiton Zakaria³, Musalmah Mazlan ${ }^{1}$, Yasmin Anum Mohd Yusof ${ }^{1}$, Aminuddin Abdul Karim ${ }^{3}$ and Wan Zurinah Wan Ngah ${ }^{1 *}$

\begin{abstract}
Background: Vitamin E supplements containing tocotrienols are now being recommended for optimum health but its effects are scarcely known. The objective was to determine the effects of Tocotrienol Rich Fraction (TRF) supplementation on lipid profile and oxidative status in healthy older individuals at a dose of $160 \mathrm{mg} / \mathrm{day}$ for 6 months.

Methods: Sixty-two subjects were recruited from two age groups: 35-49 years $(n=31)$ and above 50 years $(n=$ 31), and randomly assigned to receive either TRF or placebo capsules for six months. Blood samples were obtained at $0,3^{\text {rd }}$ and $6^{\text {th }}$ months.

Results: HDL-cholesterol in the TRF-supplemented group was elevated after 6 months $(p<0.01)$. Protein carbonyl contents were markedly decreased $(p<0.001)$, whereas AGE levels were lowered in the $>50$ year-old group $(p<$ 0.05). Plasma levels of total vitamin $E$ particularly tocopherols were significantly increased in the TRF-supplemented group after 3 months $(p<0.01)$. Plasma total tocotrienols were only increased in the $>50$ year-old group after receiving 6 months of TRF supplementation. Changes in enzyme activities were only observed in the $>50$ year-old group. SOD activity was decreased after $3(p<0.05)$ and $6(p<0.05)$ months of TRF supplementation whereas CAT activity was decreased after $3(p<0.01)$ and $6(p<0.05)$ months in the placebo group. GPx activity was increased at 6 months for both treatment and placebo groups $(p<0.05)$.

Conclusion: The observed improvement of plasma cholesterol, AGE and antioxidant vitamin levels as well as the reduced protein damage may indicate a restoration of redox balance after TRF supplementation, particularly in individuals over 50 years of age.
\end{abstract}

\section{Background}

Dietary and supplemental sources of vitamin E isoforms have been demonstrated to possess unique properties that can influence critical pathways involved in cancer $[1,2]$, cardiovascular $[3,4]$ and neurodegenerative disease $[5,6]$ development. Recent studies have identified tocotrienol, the lesser known isomer of vitamin $\mathrm{E}$ as the more effective compound in providing such protection

\footnotetext{
* Correspondence: zurina@medic.ukm.my

'Department of Biochemistry, Faculty of Medicine, Universiti Kebangsaan Malaysia, Kuala Lumpur, Malaysia

Full list of author information is available at the end of the article
}

in comparison to the well-established tocopherol [7-14]. The most promising function of tocotrienol has been reported in neuroprotection $[14,15]$ and stroke prevention with the latter being attributed to the lipid-corrective properties of tocotrienol $[11,13]$. However, most data were generated from in vitro studies or by using animal models. To date, very limited data available from human intervention study particularly involving supplemental vitamin $\mathrm{E}$ and its fundamental effects on diseases and ageing.

Recent interest has focussed on finding compounds that could intervened the chemical processes underlying

\section{Biomed Central}


age-related degenerative diseases in which has been demonstrated to be also responsible for the ageing phenomena [16,17]. Although vitamin E supplementation has yielded equivocal results in human intervention studies largely on a short term basis [18-20], supplementation studies measuring benefits to cardiovascular end points are still controversial with some showing no benefits and some even detrimental effects [21-23]. Studies are warranted to elucidate the underlying mechanism on the effects of vitamin $E$ in preventing or treating these diseases that may explain the observed effects.

Most vitamin E supplements available in the market usually contain only alpha tocopherol. However, recently with the availability of tocotrienols commercially, the uses of tocotrienol-containing supplement are more widespread. There has been a paradigm shift to vitamin E supplementation where all isomers of vitamin $E$ are recommended rather than alpha tocopherol alone [24]. However, it has yet to be determined whether supplementation with a mixture of vitamin $\mathrm{E}$ isomers containing high tocotrienol fractions will affect biochemical parameters and other blood indices and the possible underlying mechanism. We are interested in investigating age-associated biochemical changes with tocotrienol enriched vitamin $\mathrm{E}$ supplementation and identifying the specific oxidation pathways involved.

Different aged individuals respond differently to various food and vitamin supplementation [25]. Needs for supplement may be different with the different age where older people may benefit from supplementation as they were reported to have lower antioxidant levels [26].

We previously reported that TRF supplementation decreased DNA damage in healthy older adults, mostly in those over 50 years of age, and that the levels of damage were associated with age [27]. In the present work, changes in lipoprotein-lipid profile, protein carbonyl content, advanced glycosylation end products (AGEs), malondialdehyde (MDA) levels, levels of the antioxidant vitamins $\mathrm{E}$ and $\mathrm{C}$, and antioxidant activities of superoxide dismutase (SOD), catalase (CAT) and glutathione peroxidase (GPx) were measured in a randomized, double-blinded, placebo-controlled intervention study of TRF supplementation. We also studied the association between oxidative biomarkers and antioxidant levels to further elucidate the oxidant-antioxidant balance with increasing age.

\section{Methods}

\section{Study design}

Healthy volunteers were recruited through screening of a population study on oxidative stress and ageing. Selected individuals were aged 35 years and older, nonsmokers, not pregnant, not taking any vitamin supplements or minerals, alcohol, or drugs, and free of cardiac, hepatic, renal or any other chronic diseases. Adult females were recruited as the compliance from this gender is higher and mostly are non-smokers. Results of a pre-study consisting a full physical examination, previous medical history, blood chemistry and haematology were used to confirm suitability. Sixty-two subjects were recruited from two age groups, 35-49 years $(\mathrm{n}=31)$ and over 50 years $(\mathrm{n}=31)$, and randomly assigned to receive either Tocotrienol Rich Fraction (TRF) capsules $(160 \mathrm{mg} /$ day) daily in a single evening dose or an identical placebo for a period of six months. All subjects were requested to consume the capsules after dinner to ensure proper absorption $[28,29]$ and encouraged to maintain their usual lifestyle throughout the study period. The commercially prepared TRF (Tri $E^{\circledR}$ Tocotrienol) is a palm-based vitamin $E$ consisted of approximately $74 \%$ tocotrienols and $26 \%$ tocopherol in soft gelatine capsules containing palm superolein oil, and was supplied by Sime Darby Bioganic Sdn. Bhd. (previously known as Golden Hope Bioganic, Selangor, Malaysia). Each capsules contained approximately 70.4 $\mathrm{mg} \alpha$-tocotrienol, $4.8 \mathrm{mg} \beta$-tocotrienol, $57.6 \mathrm{mg} \gamma$-tocotrienol, $33.6 \mathrm{mg} \delta$-tocotrienol and $48 \mathrm{mg} \alpha$-tocopherol. The capsules given throughout the study were from the same lot and provided loosely in plastic containers. The placebo capsules contained only palm superolein oil. In addition to plasma samples for vitamin E levels, compliance was assessed by capsule counts at each 3-month interval. The amount of allotted and returned capsules for each participant is recorded during the interval visits. The treatment was double blinded throughout the study period until all data were collected, after which the randomisation code was broken. The protocol of the study was approved by the Research and Ethics Committee of the Faculty of Medicine, Universiti Kebangsaan Malaysia. Written informed consent was obtained. Subject demographics are summarised in Table 1.

\section{Sample collection}

Blood sampling was performed at baseline (month 0), 3 months and 6 months of supplementation. Venous blood samples were drawn from fasting subjects into lithium heparin-coated and $\mathrm{K}_{2}$ EDTA-containing tubes (BD Vacutainer, Becton, Dickinson and Company, Franklin Lakes, NJ, USA) for plasma extraction while into a plain tube for serum extraction. Plasma and serum were immediately separated by centrifugation at $3000 \mathrm{~g}$ for 10 minutes. The obtained packed erythrocytes were washed three times with $0.9 \%$ sodium chloride solution. Heparinized plasma aliquots were separated for lipid profiling as well as vitamin $C$ and vitamin $\mathrm{E}$ determination. Plasma-EDTA aliquots were used for protein carbonyl and MDA quantification 
Table 1 Baseline and intervention characteristics of the study groups

\begin{tabular}{|c|c|c|c|c|}
\hline & \multicolumn{2}{|c|}{ Placebo $(n=30)$} & \multicolumn{2}{|l|}{$\operatorname{TRF}(n=32)$} \\
\hline & $35-49$ years & $>50$ years & $35-49$ years & $>50$ years \\
\hline Age (years) & $44.7 \pm 0.9^{a}$ & $59.1 \pm 1.7^{\mathrm{a}}$ & $44.5 \pm 1.0^{b}$ & $56.1 \pm 1.2^{b}$ \\
\hline \multicolumn{5}{|l|}{ Blood pressure $(\mathrm{mmHg})$} \\
\hline \multicolumn{5}{|l|}{ Systolic } \\
\hline Baseline (0 month) & $121 \pm 2.8^{c}$ & $137 \pm 3.6^{c}$ & $121 \pm 3.5^{d}$ & $131 \pm 3.3^{d}$ \\
\hline 3 months & $123 \pm 2.4^{f}$ & $137 \pm 5.1^{f}$ & $121 \pm 3.4$ & $131 \pm 3.5$ \\
\hline 6 months & $120 \pm 2.5^{g}$ & $135 \pm 5.0^{g}$ & $122 \pm 3.6$ & $132 \pm 3.3$ \\
\hline \multicolumn{5}{|l|}{ Diastolic } \\
\hline Baseline (0 month) & $75.4 \pm 1.9^{\mathrm{e}}$ & $82.0 \pm 2.7^{e}$ & $80.6 \pm 2.8$ & $81.3 \pm 2.6$ \\
\hline 3 months & $73.7 \pm 1.7$ & $79.2 \pm 2.9$ & $79.2 \pm 2.6$ & $82.3 \pm 2.6$ \\
\hline 6 months & $75.7 \pm 2.8$ & $79.2 \pm 3.3$ & $79.0 \pm 3.1$ & $82.8 \pm 1.9$ \\
\hline \multicolumn{5}{|l|}{ Pulse (beat/minute) } \\
\hline Baseline (0 month) & $73 \pm 2$ & $73 \pm 3$ & $70 \pm 3$ & $70 \pm 2$ \\
\hline 3 months & $70 \pm 2$ & $72 \pm 2$ & $71 \pm 3$ & $71 \pm 2$ \\
\hline 6 months & $71 \pm 2$ & $71 \pm 3$ & $69 \pm 3$ & $72 \pm 2$ \\
\hline \multicolumn{5}{|l|}{ Body mass index $\left(\mathrm{kg} / \mathrm{m}^{2}\right)$} \\
\hline Baseline (0 month) & $27.5 \pm 1.2$ & $26.3 \pm 0.6$ & $26.3 \pm 0.7$ & $27.7 \pm 1.3$ \\
\hline 3 months & $27.5 \pm 1.2$ & $25.0 \pm 1.0$ & $25.6 \pm 0.6$ & $27.4 \pm 1.2$ \\
\hline 6 months & $26.8 \pm 1.2$ & $25.2 \pm 1.0$ & $25.7 \pm 0.7$ & $27.1 \pm 1.1$ \\
\hline \multicolumn{5}{|l|}{ Fasting blood glucose (mmol/L) } \\
\hline Baseline (0 month) & $5.53 \pm 0.33$ & $5.34 \pm 0.13$ & $5.74 \pm 0.30$ & $5.49 \pm 0.10$ \\
\hline 3 months & $5.40 \pm 0.44$ & $5.37 \pm 0.10$ & $5.59 \pm 0.22$ & $5.24 \pm 0.15$ \\
\hline 6 months & $5.55 \pm 0.49$ & $5.28 \pm 0.14$ & $5.42 \pm 0.19$ & $5.47 \pm 0.11$ \\
\hline
\end{tabular}

Values are expressed as mean \pm SEM

Same letters indicate significant difference between $35-49$ and $>50$ year-old groups.

a: $p<0.001$, b: $p<0.001$, c: $p<0.001$, d: $p<0.05$, e: $p<0.05$, f: $p<0.001$, g: $p<0.01$

whereas serum aliquots were used for AGE product testing. Washed erythrocytes were used for determination of antioxidant activities of SOD, CAT and GPx. Plasma samples for vitamin $C$ determination were deproteinised with $5 \%$ perchloric acid and centrifuged at $1000 \mathrm{~g}$ for 2 minutes, and the resulting clear supernatant was transferred into new tubes. Lipid profile testing was done immediately whereas other samples were frozen at $-80^{\circ} \mathrm{C}$ until further analysis.

\section{Lipid profile determination}

Plasma cholesterol and triglyceride concentrations were determined using enzymatic colorimetric kits (Roche diagnostics $\mathrm{GmbH}$, Indianapolis, USA) on a Hitachi 747 Automatic Analyzer (Boehringer Mannheim, Germany). High density lipoprotein-cholesterol (HDL-C) was measured using the precipitation method whereas low density lipoprotein-cholesterol (LDL-C) was calculated using Friedewald's formula.

\section{Plasma vitamin E determination}

Plasma tocopherol and tocotrienol were determined by HPLC. Briefly, stored plasma samples were thawed and aliquots of $200 \mu \mathrm{l}$ plasma and $50 \mu \mathrm{l} 95 \%$ ethanol containing $10 \mu \mathrm{g} / \mathrm{ml}$ butylated hydroxytoluene (Sigma Chemical Co., St. Louis, MO, USA) were pipetted into tubes, covered and mixed vigorously for 5 seconds. $1 \mathrm{ml}$ of absolute ethanol (Merck KGaA, Darmstadt, Germany) was then added to each tube. The tubes were covered and mixed again before being centrifuged at $1500 \mathrm{~g}$ for 15 minutes at $18^{\circ} \mathrm{C}$. The bottom pellet was carefully removed with a spatula. Hexane, $3 \mathrm{ml}$ (Merck KGaA, Darmstadt, Germany) were then added to each tube and mixed vigorously for 5 minutes. The samples were then centrifuged at $1500 \mathrm{~g}$ for 15 minutes at $18^{\circ} \mathrm{C}$. After centrifugation, a portion of the upper layer $(2.5 \mathrm{ml})$ was carefully removed, placed in new tubes and vacuum-evaporated for 40 minutes. The dried sample residue was then reconstituted in $100 \mu \mathrm{l}$ HPLC grade hexane (Merck KGaA, Darmstadt, Germany), vortexed, and passed through a $0.45 \mu \mathrm{m}$ filter to remove any non-dissolved particles. The samples were then transferred to amber vial inserts with care taken to avoid air bubbles and analysed by HPLC using a Shimadzu RF-10A XL fluorescence detector (Shimadzu Corporation, Kyoto, Japan) at an excitation wavelength of $294 \mathrm{~nm}$ and an emission wavelength of $330 \mathrm{~nm}$. Isomers $\alpha$-tocopherol, $\gamma$-tocopherol, $\alpha$-tocotrienol, $\gamma$-tocotrienol and $\delta$-tocotrienol 
were separated on a $250 \mathrm{~mm} \times 4.6 \mathrm{~mm}, 5 \mu \mathrm{m}$ Allsphere Silica column (Alltech Associated, Inc, IL, USA) and eluted with a mobile phase of 99:1 (v/v) hexane-isopropanol at a flow rate of $1.5 \mathrm{ml}$ per minute. The identity of each compound was confirmed by co-elution with spiked standard. All external standards used were obtained from Malaysian Palm Oil Board (MPOB), Malaysia. The peaks were quantified and integrated with Shimadzu Class-VPTM version 6.1 LC Workstation software (Shimadzu Corporation, Kyoto, Japan).

\section{Plasma vitamin C determination}

The measurement of plasma vitamin $C$ (ascorbic acid) was performed using HPLC as described by Pachla and Kissinger [30]. Plasma ascorbic acid was chromatographically separated on a $25 \mathrm{~cm}$ VYDAC $^{\circledR}$ Genesis C-18 4 $\mu \mathrm{m}$ column (Grace Davison, USA) using a mobile phase containing $0.04 \mathrm{M}$ sodium acetate, $0.48 \mathrm{mM}$ disodium EDTA, $2.9 \mathrm{mM}$ tetrabutylammonium hydroxide and $1.4 \%$ methanol at $\mathrm{pH} 4.75$. Detection was performed on an electrochemical detector (Gilson model 142, Gilson Medical Electronics S.A., Villiers-le-Bel, France) set at an applied potential of $+700 \mathrm{mV}$ and referenced to an $\mathrm{Ag} / \mathrm{AgCl}$ electrode, with a flow rate of $1 \mathrm{ml} / \mathrm{min}$ and sensitivity of $100 \mathrm{nA} / \mathrm{V}$ on a Gilson HPLC set (Gilson Medical Electronics S.A., Villiers-le-Bel, France). Assay calibration was performed for each run using six concentrations of the calibrator $(0,2,4,6,8,10$ and $12 \mathrm{mg} /$ L). Stored deproteinised plasma samples were thawed, added with $5 \mathrm{mg} / \mathrm{L}$ 3,4-dihydroxybenzylamine (Sigma Chemical Co., USA) and spiked with $5 \mathrm{mg} / \mathrm{L}$ ascorbic acid (Sigma Chemical Co., St. Louis, MO, USA). 3,4dihydroxybenzylamine was added to all samples and calibrators as an internal standard whereas uric acid Raichem $^{\mathrm{TM}}$ (Reagents Applications Inc., USA) was injected separately for peak identification. All samples were filtered through a $0.45 \mu \mathrm{m}$ membrane before being subjected to HPLC and all peaks were baseline separated. Ascorbic acid, 3,4-dihydroxybenzylamine and uric acid peaks were resolved and detected within 11 minutes of run time and were identified using the retention times of calibrators. Peaks were integrated using peak-area ratios of ascorbic acid to 3,4-dihydroxybenzylamine.

\section{Plasma protein carbonyl determination}

Carbonyl content in oxidatively-modified proteins was assayed using the Cayman Chemical protein carbonyl assay kit (Cayman Chemical Company, Ann Arbor, MI, USA) based on the method of Levine et al. [31] by following the manufacturer instructions. Briefly, 2,4-dinitrophenyl-hydrazine (DNPH) reacts with protein carbonyls, forming a Schiff base to produce the corresponding hydrazone. The protein-hydrazone produced was quantified at an absorbance of $370 \mathrm{~nm}$ with an extinction coefficient of 22,000 $\mathrm{M}^{-1} \mathrm{~cm}^{-1}$. Each sample was assayed with a parallel control and the concentration of carbonyls was determined after correction with the respective control. The carbonyl content was then standardized against the protein concentration in the sample and expressed as nmol carbonyl per mg protein. The amount of protein was calculated from a bovine serum albumin (Sigma Chemical Co., St. Louis, USA) standard curve $(0.25-2.0 \mathrm{mg} / \mathrm{ml})$ read at $280 \mathrm{~nm}$.

\section{Serum AGE determination}

Serum advanced glycosylation end products (AGEs) was measured with an in-house competitive enzyme immunoassay technique developed by Wan Nazaimoon and Khalid [32]. Briefly, microtitre wells were coated with AGE-BSA at $8 \mu \mathrm{g} / \mathrm{ml}$ followed by an overnight incubation with $20 \mu \mathrm{l}$ of the prediluted sample (1:6) and $80 \mu \mathrm{l}$ anti-AGE-KLH (1:8000). HRP-labelled goat anti-rabbit $(1: 3000)$ was used as the secondary antibody and 3,5',5,5'-tetramethylbenzidine dihydrochloride (Sigma Chemical Co., St. Louis, USA) as the substrate. The colour reaction was stopped with $1.25 \mathrm{M}$ sulphuric acid and the absorbance was read at $450 \mathrm{~nm}$ with reference at $620 \mathrm{~nm}$. All samples were assayed in triplicate and assay performance was monitored using a set of inhouse quality control sera containing three different levels of AGE.

\section{Plasma MDA determination}

Plasma malondialdehyde (MDA) was determined by HPLC based on the derivatisation of MDA with 2,4dinitrophenylhydrazine (DNPH) (Sigma-Aldrich, St. Louis, MO, USA) as described by Pilz et al. [33] with some modifications. Briefly, stored plasma samples were thawed and aliquots of $250 \mu \mathrm{l}$ plasma were mixed with $50 \mu \mathrm{l} 6 \mathrm{M}$ sodium hydroxide (Merck, Germany). The sample mixture was incubated at $60^{\circ} \mathrm{C}$ for 30 minutes in a water bath. After cooling to room temperature, the hydrolysed sample was then acidified with $125 \mu \mathrm{l} 35 \%$ $(\mathrm{v} / \mathrm{v})$ perchloric acid to precipitate proteins and centrifuged at $6000 \mathrm{~g}$ for 10 minutes at $18^{\circ} \mathrm{C}$. The supernatant was transferred into fresh tubes and the sample was then derivatised with $50 \mu \mathrm{l} 5 \mathrm{mM}$ DNPH for 30 minutes at room temperature. Derivatised samples were used for HPLC analysis and protected from light from this step onwards.

Analytical HPLC separations were performed on a Shimadzu Chromatographic system (Shimadzu Class$\mathrm{VP}^{\text {TM }}$ version 6.1 LC Workstation software, Shimadzu Corporation, Kyoto, Japan) with a diode array detector equipped with an auto injector and operated at $310 \mathrm{~nm}$ on a $150 \mathrm{~mm} \times 3.9 \mathrm{~mm}, 5 \mu \mathrm{m}$ alphaBond C18 column (Alltech Associated, Inc. IL, USA). Samples and standards were eluted with a mobile phase consisting of 380 
$\mathrm{ml}$ acetonitrile with $620 \mathrm{ml}$ of distilled water, acidified with $0.2 \%(\mathrm{v} / \mathrm{v})$ acetic acid and degassed at a flow rate of $0.6 \mathrm{ml} / \mathrm{min}$. The plasma MDA level was calculated from a calibration curve prepared by acidic hydrolysis of 1,1,3,3-Tetraethoxypropane (TEP) (Sigma-Aldrich, St. Louis, MO, USA).

\section{Determination of erythrocyte antioxidant enzymes}

SOD, CAT and GPx activities in the hemolysates were expressed as U/mg Hb. Erythrocyte $\mathrm{Cu}, \mathrm{Zn}$-SOD activity was assayed using the spectrophotometric indirect inhibition technique of Beyer and Fridovich, which is based on the ability of SOD to inhibit the photoreduction of nitro blue tetrazolium [34]. CAT activity was measured in erythrocytes using the method of Aebi [35] with hydrogen peroxide as the substrate. This method is based on the decomposition of hydrogen peroxide and measured by decreased absorbance at $240 \mathrm{~nm}$. GPx activity was measured in erythrocytes using the coupled method of Paglia and Valentine with $t$-butyl hydroperoxide as the substrate [36]. Hemoglobin was assayed using the cyanmethemoglobin procedure (Eagle Diagnostics, Desoto, Texas, USA) based on the determination of cyanmethemoglobin at $540 \mathrm{~nm}$.

\section{Statistical Analysis}

Statistical analysis was performed using Statistical Package for Social Sciences (SPSS) Version 11.5 (Chicago, Illinois, USA). Mixed model analysis of variance (ANOVA) was used to compare changes from baseline to 3 and 6 months for all variables to ascertain the effects of treatment. One way analysis of variance was used to identify significant differences between age groups. The associations of all parameters were assessed by partial correlations and analyses of covariance to account for the increased proportion of women in the study group. Pearson's correlation coefficient was determined for baseline variables to determine their relationships. Mauchly's test of sphericity was used to assess the homogeneity of variance and Dunnett's test was performed to compare the means of the treatment group to the means of the control group. Bonferroni's adjustment was applied to control the inflation of Type 1 error across multiple tests. All data are presented as mean \pm standard error of the mean (SEM). The null hypothesis was tested using a 2 -tailed $\alpha<0.05$ criterion. PS Program version 2.1.31 was used to determine the power of study in which the probability of rejecting the null hypothesis with Type I error was set at $\alpha=0.05$, given the specified sample size $n=30$, a standard deviation $\sigma$ $=0.104$ and when the true difference in population means was $\delta=0.097$. The statistical power obtained from our approach was 0.9977 .

\section{Results}

\section{Subject characteristics}

The baseline characteristics of subject age, gender, blood pressure, pulse, body mass index and fasting blood glucose in the TRF groups were similar to those in the placebo groups (Table 1). Systolic and diastolic blood pressure in the younger group (35-49 years old) were significantly lower than those in the older group (over 50 years old) while no significant differences was observed between groups regarding to pulse, body mass index (BMI) or fasting blood sugar (FBS). None of these clinical parameters showed statistical difference upon supplementation except for BMI (Table 1) where the younger group who received TRF demonstrated reductions in BMI at 3 months $(\mathrm{p}=0.024)$ and 6 months ( $\mathrm{p}$ $<0.001)$.

\section{Lipid profile}

Plasma total cholesterol was within the normal range in all subjects before supplementation. There was no significant difference in lipids level between the younger and older groups at baseline (Table 2). A statistically significant effect for duration of treatment was observed in HDL-C in TRF group ( $F=4.196, p=0.020$, effect size $=0.139$, power $=0.713)$. The HDL-C level in the younger group increased significantly after 6 months of Tocotrienol supplementation $(\mathrm{p}=0.014)$ as compared to the baseline, while in the $>50$ year-old group, a nonsignificant elevation of $8 \%$ was observed. However, the plasma ratio of HDL-C to total cholesterol improved in both younger $(p=0.007)$ and older groups $(p=0.029)$ with supplementation. Values obtained for all lipid variables were within the normal range.

\section{Antioxidant vitamins}

Plasma vitamin E levels were corrected for cholesterol levels. Increased plasma total vitamin $\mathrm{E}$ concentrations were evident after 3 months in the treatment group ( $\mathrm{F}=$ 9.491, $\mathrm{p}=0.006$, effect size $=0.311$, power $=0.836$ ) but not in placebo group (Table 3). Further grouping of subjects by age (Table 4) revealed significant increases in lipid-corrected total vitamin $\mathrm{E}$ in both 35-49 year-old and $>50$ year-old groups after 6 months $(\mathrm{F}=10.233$, $\mathrm{p}$ $=0.011$, effect size $=0.532$, power $=0.812$ and $\mathrm{F}=$ $43.707, \mathrm{p}<0.001$, effect size $=0.785$, power $=1$ respectively), but in the $>50$ year-old group, levels had significantly increased as early as 3 months after starting treatment $(\mathrm{F}=6.933, \mathrm{p}=0.022$, effect size $=0.366$, power $=0.677)$.

Similar results were observed for plasma tocopherol concentration. Changes in plasma level of tocopherol were statistically significant with duration of treatment $(\mathrm{F}=12.896, \mathrm{p}<0.001$, effect size $=0.380$, power $=$ 
Table 2 Lipid profiles of study groups

\begin{tabular}{|c|c|c|c|c|}
\hline & \multicolumn{4}{|c|}{ Age group } \\
\hline & \multicolumn{2}{|c|}{$35-49$ years } & \multicolumn{2}{|c|}{$>50$ years } \\
\hline & Placebo & TRF & Placebo & TRF \\
\hline \multicolumn{5}{|l|}{$\mathrm{TC}(\mathrm{mmol} / \mathrm{L})$} \\
\hline Baseline (0 month) & $5.12 \pm 0.19$ & $5.34 \pm 0.18$ & $5.30 \pm 0.20$ & $5.43 \pm 0.19$ \\
\hline 3 months & $4.91 \pm 0.17$ & $5.39 \pm 0.16$ & $5.39 \pm 0.18$ & $5.43 \pm 0.20$ \\
\hline 6 months & $5.04 \pm 0.17$ & $5.47 \pm 0.15$ & $5.34 \pm 0.21$ & $5.44 \pm 0.20$ \\
\hline \multicolumn{5}{|l|}{$\mathrm{HDL}-\mathrm{C}(\mathrm{mmol} / \mathrm{L})$} \\
\hline Baseline (0 month) & $1.37 \pm 0.07$ & $1.24 \pm 0.07$ & $1.35 \pm 0.09$ & $1.36 \pm 0.10$ \\
\hline 3 months & $1.42 \pm 0.10$ & $1.32 \pm 0.06$ & $1.47 \pm 0.07$ & $1.32 \pm 0.10$ \\
\hline 6 months & $1.41 \pm 0.10$ & $1.42 \pm 0.07^{*}$ & $1.28 \pm 0.07^{\mathrm{a}}$ & $1.47 \pm 0.07^{a}$ \\
\hline \multicolumn{5}{|l|}{ LDL-C (mmol/L) } \\
\hline Baseline (0 month) & $3.28 \pm 0.18$ & $3.40 \pm 0.20$ & $3.28 \pm 0.20$ & $3.42 \pm 0.15$ \\
\hline 3 months & $2.99 \pm 0.17$ & $3.45 \pm 0.15$ & $3.18 \pm 0.17$ & $3.45 \pm 0.18$ \\
\hline 6 months & $3.15 \pm 0.17$ & $3.40 \pm 0.15$ & $3.53 \pm 0.16$ & $3.23 \pm 0.18$ \\
\hline \multicolumn{5}{|l|}{ Triglycerides (mmol/L) } \\
\hline Baseline (0 month) & $1.12 \pm 0.15$ & $1.39 \pm 0.20$ & $1.41 \pm 0.19$ & $1.46 \pm 0.26$ \\
\hline 3 months & $1.23 \pm 0.12$ & $1.25 \pm 0.17$ & $1.58 \pm 0.23$ & $1.44 \pm 0.25$ \\
\hline 6 months & $1.02 \pm 0.10^{b}$ & $1.48 \pm 0.25$ & $1.45 \pm 0.25^{b}$ & $1.57 \pm 0.30$ \\
\hline \multicolumn{5}{|l|}{$\mathrm{HDL}-\mathrm{C} / \mathrm{TC}$} \\
\hline Baseline (0 month) & $26.58 \pm 1.44$ & $23.14 \pm 1.63$ & $26.30 \pm 2.26$ & $24.73 \pm 1.56$ \\
\hline 3 months & $28.53 \pm 1.97$ & $24.82 \pm 1.36$ & $27.30 \pm 2.21$ & $24.53 \pm 1.81$ \\
\hline 6 months & $28.89 \pm 1.67$ & $25.91 \pm 1.53^{* *}$ & $24.92 \pm 1.82^{c}$ & $28.13 \pm 1.52^{* c}$ \\
\hline
\end{tabular}

Values are expressed as mean \pm SEM

Abbreviations: TC, total cholesterol; HDL-C, high-density lipoprotein-cholesterol; LDL-C, low density lipoprotein-cholesterol

Symbols indicate significant difference from baseline (0 month)

*: $p<0.05,{ }^{* *}: p<0.01$

Same characters indicate significant difference as compared to placebo group.

a: $p=0.022$, b: $p=0.022, c: p=0.04$

0.995). Supplementation with TRF markedly increased lipid-corrected total tocopherol levels after 3 and 6 months in the $>50$ year-old group $(\mathrm{F}=8.043, \mathrm{p}=$ 0.015 , effect size $=0.401$, power $=0.740$ and $F=47.069$, $\mathrm{p}<0.000$, effect size $=0.797$, power $=1$ respectively) as compared to the younger age group. The 35-49 year-old group only showed increased levels of lipid-corrected tocopherols after 6 months of supplementation $(\mathrm{F}=$ 9.445, $\mathrm{p}=0.013$, effect size $=0.512$, power $=0.781$ ).

Overall, lipid-corrected tocotrienol levels were significantly increased in TRF supplemented subjects when compared to baseline and placebo-receiving subjects after 6 months $(\mathrm{F}=10.068, \mathrm{p}=0.005$, effect size $=$ 0.324 , power $=0.857)$. However, further increases in tocotrienol levels were only observed in the $>50$ yearold group after 6 months of treatment $(\mathrm{F}=11.197, \mathrm{p}=$ 0.006 , effect size $=0.483$, power $=0.866$ ). Regardless of the treatment type, levels of lipid-corrected total tocotrienols in the older group were lower than in the younger group. With treatment, however, levels of lipidcorrected total tocotrienols in older subjects approached levels observed in younger subjects.

Table 3 Plasma antioxidant vitamins in placebo and TRF groups

\begin{tabular}{|c|c|c|c|c|c|c|}
\hline \multirow{3}{*}{ Antioxidant vitamins } & \multicolumn{6}{|c|}{ Duration } \\
\hline & \multicolumn{2}{|c|}{0 month } & \multicolumn{2}{|c|}{3 months } & \multicolumn{2}{|c|}{6 months } \\
\hline & Placebo & TRF & Placebo & TRF & Placebo & TRF \\
\hline Lipid-corrected total vitamin E (g/mol) & $9.76 \pm 0.38$ & $9.35 \pm 0.39$ & $10.02 \pm 0.20$ & $10.44 \pm 0.35^{* *}$ & $9.26 \pm 0.45$ & $11.74 \pm 0.57^{* *}$ \\
\hline Lipid-corrected total tocopherol $(\mathrm{g} / \mathrm{mol})$ & $9.16 \pm 0.37$ & $8.78 \pm 0.40$ & $9.53 \pm 0.22$ & $9.83 \pm 0.37^{* *}$ & $8.55 \pm 0.41$ & $10.96 \pm 0.54^{* *}$ \\
\hline Lipid-corrected total tocotrienol ( $\mathrm{g} / \mathrm{mol})$ & $0.63 \pm 0.07$ & $0.57 \pm 0.06$ & $0.54 \pm 0.06$ & $0.62 \pm 0.06$ & $0.69 \pm 0.08$ & $0.78 \pm 0.07^{* *}$ \\
\hline Vitamin C (mg/L) & $5.09 \pm 0.30$ & $4.23 \pm 0.26$ & $5.86 \pm 0.30^{*}$ & $5.29 \pm 0.29^{* *}$ & $6.07 \pm 0.31^{* *}$ & $5.14 \pm 0.37^{* *}$ \\
\hline
\end{tabular}

Values are expressed as mean \pm SEM.

Symbols indicate significant difference from baseline (0 month).

*: $p<0.05,{ }^{* *}: p<0.01$ 
Table 4 Plasma antioxidant vitamins according to age group

\begin{tabular}{|c|c|c|c|c|}
\hline \multirow{3}{*}{ Antioxidant vitamins } & \multicolumn{4}{|c|}{ Age group } \\
\hline & \multicolumn{2}{|c|}{$35-49$ years } & \multicolumn{2}{|c|}{$>50$ years } \\
\hline & Placebo & TRF & Placebo & TRF \\
\hline \multicolumn{5}{|c|}{ Lipid-corrected total vitamin E ( $\mathrm{g} / \mathrm{mol})$} \\
\hline Baseline (0 month) & $8.71 \pm 0.37$ & $8.57 \pm 0.43$ & $10.41 \pm 0.50$ & $9.89 \pm 0.56$ \\
\hline 3 months & $9.49 \pm 0.24$ & $9.59 \pm 0.46$ & $10.35 \pm 0.25$ & $11.03 \pm 0.45^{*}$ \\
\hline 6 months & $9.04 \pm 0.67$ & $10.39 \pm 0.53^{* *}$ & $9.52 \pm 0.61$ & $12.89 \pm 0.85^{* *}$ \\
\hline \multicolumn{5}{|c|}{ Lipid-corrected total tocopherol (g/mol) } \\
\hline Baseline (0 month) & $8.04 \pm 0.33$ & $7.89 \pm 0.45$ & $9.84 \pm 0.47$ & $9.39 \pm 0.57$ \\
\hline 3 months & $8.92 \pm 0.35$ & $8.86 \pm 0.46$ & $9.92 \pm 0.29$ & $10.49 \pm 0.48^{*}$ \\
\hline 6 months & $8.20 \pm 0.62$ & $9.66 \pm 0.52^{* *}$ & $8.97 \pm 0.52$ & $12.06 \pm 0.79^{* *}$ \\
\hline \multicolumn{5}{|c|}{ Lipid-corrected total tocotrienol (g/mol) } \\
\hline Baseline (0 month) & $0.69 \pm 0.09$ & $0.66 \pm 0.08$ & $0.58 \pm 0.11$ & $0.50 \pm 0.07$ \\
\hline 3 months & $0.61 \pm 0.07$ & $0.73 \pm 0.11$ & $0.46 \pm 0.09$ & $0.54 \pm 0.07$ \\
\hline 6 months & $0.80 \pm 0.09$ & $0.73 \pm 0.09$ & $0.55 \pm 0.14$ & $0.82 \pm 0.11^{* *}$ \\
\hline \multicolumn{5}{|l|}{ Vitamin C (mg/L) } \\
\hline Baseline (0 month) & $4.61 \pm 0.35$ & $3.95 \pm 0.19$ & $5.57 \pm 0.47$ & $4.50 \pm 0.48$ \\
\hline 3 months & $5.26 \pm 0.42$ & $5.16 \pm 0.43^{*}$ & $6.48 \pm 0.36$ & $5.42 \pm 0.39^{*}$ \\
\hline 6 months & $5.66 \pm 0.32^{* *}$ & $4.98 \pm 0.63$ & $6.66 \pm 0.56$ & $5.26 \pm 0.46^{* *}$ \\
\hline
\end{tabular}

Values are expressed as mean \pm SEM.

Symbols indicate significant difference from baseline (0 month).

*: $p<0.05,{ }^{* *}: p<0.01$

Plasma vitamin $\mathrm{C}$ concentrations increased in both groups regardless of the treatment received. Further analysis of age groups showed similar increases for all groups to varying degrees of significance.

\section{Antioxidant enzymes}

A significant effect for duration was observed in SOD activity with TRF treatment $(\mathrm{F}=6.838, \mathrm{p}=0.006$, effect size $=0.229$, power $=0.826)$ as well as in CAT and GPx activity with placebo $(\mathrm{F}=4.185, \mathrm{p}=0.002$, effect size $=$ 0.160 , power $=0.707$ and $F=5.271, p=0.009$, effect size $=0.193$, power $=0.809$ respectively). SOD activity decreased after 3 and 6 months of TRF treatment (Table 5); these effects were seen in both younger and older groups, although only the $>50$ year-old group reached statistical significance (Table 6). CAT activity was decreased in the placebo group after 3 months; this change was also only observed in the $>50$ year-old group. Similar effects were observed for GPx, where only subjects in the $>50$ year-old group showed increased activity after 6 months regardless of treatment.

There was nearly no association between SOD activity and age (Figure 1), whereas GPx activity slightly declined with age (Figure 2), while CAT activity slightly increased with age (Figure 3); however, none of these correlations was significant. Supplementation with TRF strengthened the relationship between SOD activity and age as well as for CAT activity. GPx activity was reversed in the older individuals in association with age.

\section{Oxidative markers}

Changes in protein carbonyl levels were statistically significant with duration of treatment $(\mathrm{F}=6.193, \mathrm{p}=$ 0.008 , effect size $=0.212$, power $=0.810$ ). Protein carbonyl content was significantly decreased after 6 months of TRF treatment $(\mathrm{p}=0.002)$ as compared to baseline

Table 5 Erythrocyte antioxidant enzymes activity in placebo and TRF groups

\begin{tabular}{|c|c|c|c|c|c|c|}
\hline \multirow{3}{*}{ Antioxidant enzymes } & \multicolumn{6}{|c|}{ Duration } \\
\hline & \multicolumn{2}{|c|}{0 month } & \multicolumn{2}{|c|}{3 months } & \multicolumn{2}{|c|}{6 months } \\
\hline & Placebo & TRF & Placebo & TRF & Placebo & TRF \\
\hline Superoxide dismutase (U/mg Hb) & $1.90 \pm 0.09$ & $2.29 \pm 0.14$ & $1.90 \pm 0.16$ & $1.83 \pm 0.09^{* *}$ & $1.91 \pm 0.13$ & $1.77 \pm 0.09^{* *}$ \\
\hline Catalase (U/mg Hb) & $0.30 \pm 0.01$ & $0.28 \pm 0.01$ & $0.24 \pm 0.01^{* *}$ & $0.27 \pm 0.01$ & $0.27 \pm 0.01$ & $0.27 \pm 0.01$ \\
\hline Glutathione peroxidase (U/mg Hb) & $0.82 \pm 0.05$ & $0.87 \pm 0.04$ & $0.87 \pm 0.05$ & $1.04 \pm 0.08$ & $1.04 \pm 0.05^{* *}$ & $1.09 \pm 0.06^{*}$ \\
\hline
\end{tabular}

Values are expressed as mean \pm SEM

Symbols indicate significant difference from baseline ( 0 month).

*: $p<0.05,{ }^{* *}: p<0.01$ 
Table 6 Erythrocyte antioxidant enzymes activity according to age group

\begin{tabular}{|c|c|c|c|c|}
\hline \multirow{3}{*}{ Antioxidant enzymes } & \multicolumn{4}{|c|}{ Age group } \\
\hline & \multicolumn{2}{|c|}{$35-49$ years } & \multicolumn{2}{|c|}{$>50$ years } \\
\hline & Placebo & TRF & Placebo & TRF \\
\hline \multicolumn{5}{|c|}{ Superoxide dismutase (U/mg Hb) } \\
\hline Baseline (0 month) & $1.85 \pm 0.14$ & $2.23 \pm 0.22$ & $1.89 \pm 0.12$ & $2.35 \pm 0.20$ \\
\hline 3 months & $1.95 \pm 0.16$ & $1.81 \pm 0.15$ & $1.85 \pm 0.28$ & $1.85 \pm 0.12^{*}$ \\
\hline 6 months & $1.98 \pm 0.24$ & $1.74 \pm 0.14$ & $1.85 \pm 0.10$ & $1.79 \pm 0.12^{*}$ \\
\hline \multicolumn{5}{|l|}{ Catalase (U/mg Hb) } \\
\hline Baseline (0 month) & $0.29 \pm 0.02$ & $0.28 \pm 0.02$ & $0.32 \pm 0.02$ & $0.28 \pm 0.01$ \\
\hline 3 months & $0.25 \pm 0.01$ & $0.25 \pm 0.02$ & $0.23 \pm 0.01^{* *}$ & $0.29 \pm 0.02$ \\
\hline 6 months & $0.29 \pm 0.02$ & $0.23 \pm 0.02$ & $0.24 \pm 0.02^{*}$ & $0.30 \pm 0.02$ \\
\hline \multicolumn{5}{|c|}{ Glutathione peroxidase $(\mathrm{U} / \mathrm{mg} \mathrm{Hb})$} \\
\hline Baseline (0 month) & $0.74 \pm 0.07$ & $0.89 \pm 0.06$ & $0.90 \pm 0.06$ & $0.86 \pm 0.06$ \\
\hline 3 months & $0.87 \pm 0.10$ & $1.02 \pm 0.15$ & $0.88 \pm 0.06$ & $1.07 \pm 0.08$ \\
\hline 6 months & $0.88 \pm 0.06$ & $1.05 \pm 0.13$ & $1.19 \pm 0.06^{*}$ & $1.12 \pm 0.06^{*}$ \\
\hline
\end{tabular}

Values are expressed as mean \pm SEM.

Symbols indicate significant difference from baseline ( 0 month).

*: $p<0.05,{ }^{* *}: p<0.01$

(0 month) (Table 7$)$. Further grouping by age (Table 8 ) revealed a marked reduction $(\mathrm{p}<0.001)$ in the $>50$ year-old group after 6 months of treatment. Nonetheless, no significant effect for duration was obtained in AGE and MDA levels despite both levels were reduced in the older TRF-treated group after 3 months and remained low thereafter; however, this tendency did not reach significance.

The relationships between age and oxidative stress marker levels are shown in Figures 4, 5 and 6. All measured biomarkers (protein carbonyl, AGE and MDA) were weakly correlated with age. TRF treatment reversed

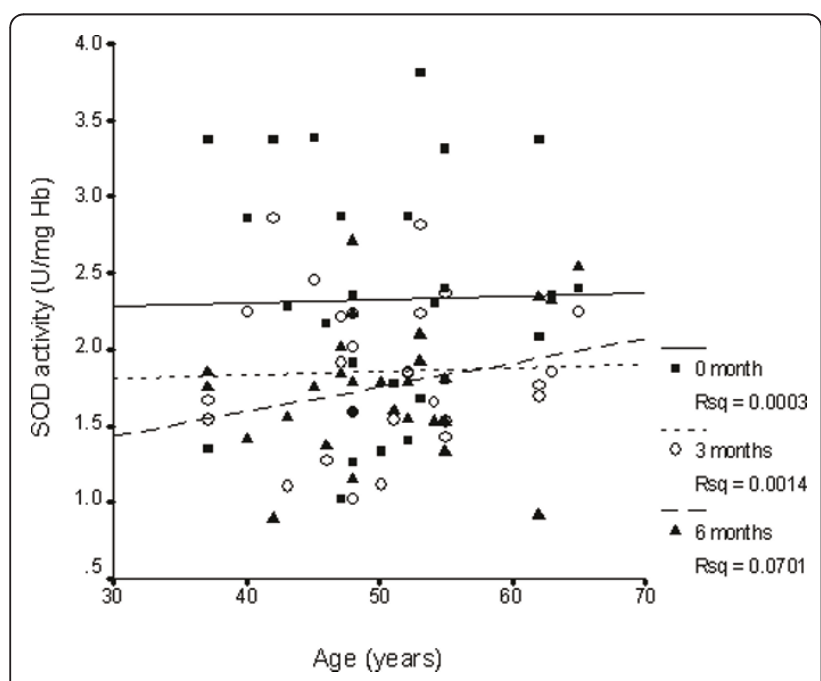

Figure 1 Correlation between superoxide dismutase activity and age with TRF treatment for 6 months. TRF supplementation strengthened the association after 6 months. 0 month: $r=0.04, p=$ $0.81 ; 3$ months: $r=0.06, p=0.73 ; 6$ months: $r=0.26, p=0.21$. these relationships, particularly for MDA, which showed a correlation coefficient of close to $0.4(\mathrm{p}<0.05)$.

\section{Discussion}

Human ageing is affected by both genetic factors and lifestyle-related factors such as diet. Dietary intervention is feasible, as nutrients can affect the rate of ageing by altering the type and quantity of proteins synthesized [37] by modulating gene expression [38], thereby altering the oxidative status of individuals [39].

Our results indicate that daily supplementation for up to 6 months with TRF raised plasma HDL cholesterol

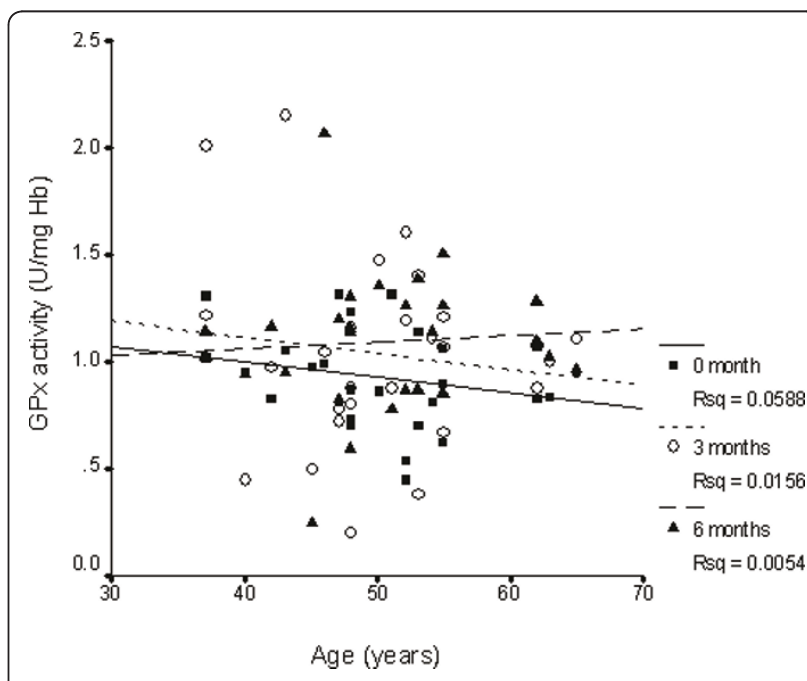

Figure 2 Correlation between glutathione peroxidase activity and age with TRF treatment for 6 months. TRF supplementation reversed the relationship after 6 months. 0 month: $r=-0.17, p=$ $0.40 ; 3$ months: $r=-0.16, p=0.41 ; 6$ months: $r=0.05, p=0.82$. 


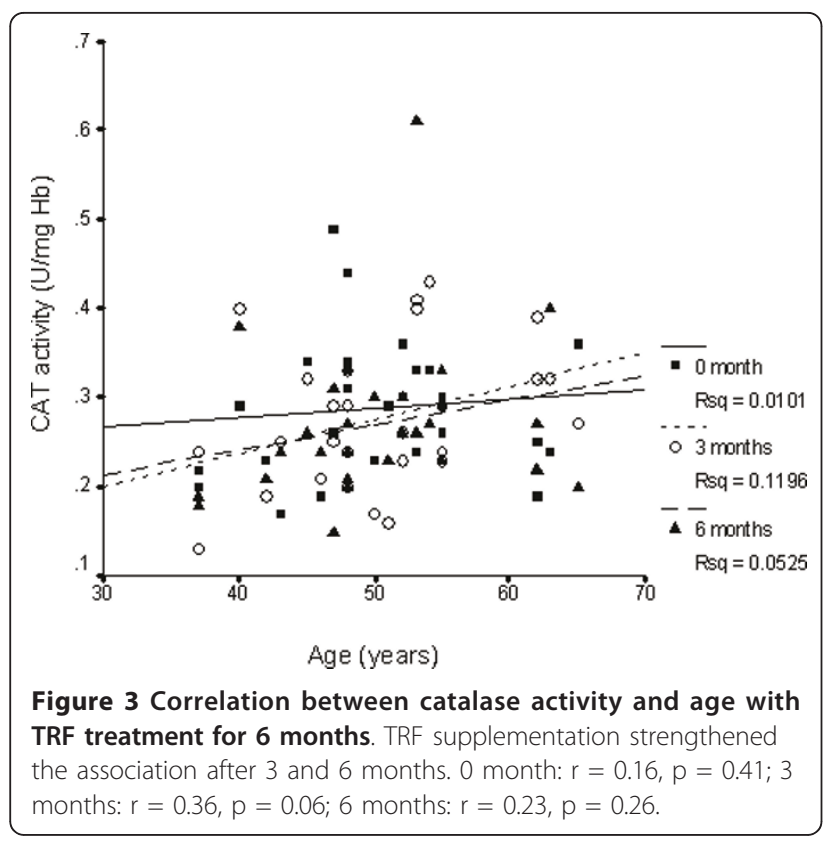

levels as early as 3 months, thereby increasing the HDLcholesterol/total cholesterol ratio. This ratio reflects the proportion of anti-atherogenic to atherogenic lipids and has been suggested as a better predictor of cardiovascular disease risk than the individual lipoprotein values [40]. TRF might thus help to reduce the risk of coronary heart disease (CHD) in healthy older adults. In fact, HDL cholesterol increases of the magnitude observed in this study have been associated with a $22.5 \%$ reduced risk of cardiovascular events [41]. Raising plasma HDL cholesterol and thus the HDL-cholesterol/total cholesterol is recommended by the American Diabetes Association (ADA) guidelines together with lowering plasma triglycerides for high-risk individuals particularly older adults as major mortality cases of CHD were 65 years old or older [42].

Conflicting data have been reported regarding effects of vitamin E supplementation which were mainly $\alpha$ tocopherol on HDL cholesterol. Increased HDL cholesterol after $\alpha$-tocopherol supplementation has been reported by some investigators [43-45] and disputed by others $[46,47]$. It should be noted that the supplement used in this study was high in tocotrienols, which has been reported to have different effect from $\alpha$-tocopherol [48]. Tocotrienol but not tocopherol increases HDL cholesterol by inhibiting HMG-CoA reductase through signalling, thereby regulating cholesterol biosynthesis [49]. Tocotrienol may increase HDL in this study by modulating signal transduction and gene expression; specifically, and may normalize any aberrant gene expression incurred by aging [50]. Increases in HDL could be attained by increasing physical exercise $[51,52]$ but similar effects by supplementation of vitamins have not been reported in human.

Compliance of the subjects was indicated by the observed increase in plasma lipid-corrected total tocotrienol and tocopherol concentration. Standardization of plasma vitamin E levels to total cholesterol was necessary to control for age-related changes in baseline cholesterol levels as vitamin $E$ is transported by the lipoproteins. The finding that tocotrienol levels were increased is of particular interest, as tocotrienol is now reported to have functions distinct from $\alpha$-tocopherol as reviewed by Sen et al. [53]. The marked increase in tocotrienol in the $>50$ age group is interesting and suggests an increased bioavailability and possibly the need for tocotrienol with aging. The level of total tocotrienol was slightly lower in the older adults as opposed to the younger group. Supplementation of older subjects with TRF restored plasma vitamin $E$ availability to near the levels of in the controls of the younger group. We speculate that a steady state plasma vitamin E concentration was achieved after 6 months of supplementation, as plasma concentrations were similar to those in the younger group were seen at that time point. Some studies have reported the achievement of steady-state plasma vitamin E levels after 10 to 15 days of supplementation with either natural or synthetic forms of $\alpha$ tocopherol at much higher dosages [54-56]. Considering the well-documented preferential absorption and transportation of different vitamin $\mathrm{E}$ isomers in the body and

Table 7 Oxidative markers in placebo and TRF groups

\begin{tabular}{|c|c|c|c|c|c|c|}
\hline \multirow{3}{*}{ Oxidative Markers } & \multicolumn{6}{|c|}{ Duration } \\
\hline & \multicolumn{2}{|c|}{0 month } & \multicolumn{2}{|c|}{3 months } & \multicolumn{2}{|c|}{6 months } \\
\hline & Placebo & TRF & Placebo & TRF & Placebo & TRF \\
\hline Protein carbonyl (nmol/mg) & $0.52 \pm 0.05$ & $0.63 \pm 0.04$ & $0.51 \pm 0.05$ & $0.53 \pm 0.04$ & $0.56 \pm 0.05$ & $0.45 \pm 0.04^{* *}$ \\
\hline Advanced glycosylation end-product (units/ml) & $2.37 \pm 0.11$ & $2.38 \pm 0.19$ & $2.00 \pm 0.15$ & $2.40 \pm 0.18$ & $1.93 \pm 0.17$ & $1.92 \pm 0.14$ \\
\hline Malondialdehyde (nmol/ml) & $4.21 \pm 0.19$ & $4.10 \pm 0.30$ & $4.00 \pm 0.24$ & $3.90 \pm 0.25$ & $3.91 \pm 0.23$ & $4.14 \pm 0.22$ \\
\hline
\end{tabular}

Values are expressed as mean \pm SEM.

Symbols indicate significant difference from baseline ( 0 month).

**: $p<0.01$ 
Table 8 Oxidative markers according to age group

\begin{tabular}{|c|c|c|c|c|}
\hline \multirow{3}{*}{ Oxidative markers } & \multicolumn{4}{|c|}{ Age group } \\
\hline & \multicolumn{2}{|c|}{$35-49$ years } & \multicolumn{2}{|c|}{$>50$ years } \\
\hline & Placebo & TRF & Placebo & TRF \\
\hline \multicolumn{5}{|c|}{ Protein carbonyl (nmol/mg) } \\
\hline Baseline (0 month) & $0.54 \pm 0.08$ & $0.58 \pm 0.08$ & $0.50 \pm 0.06$ & $0.63 \pm 0.03$ \\
\hline 3 months & $0.56 \pm 0.13$ & $0.54 \pm 0.05$ & $0.48 \pm 0.05$ & $0.52 \pm 0.06$ \\
\hline 6 months & $0.60 \pm 0.08$ & $0.51 \pm 0.06$ & $0.47 \pm 0.04$ & $0.40 \pm 0.03^{* *}$ \\
\hline \multicolumn{5}{|c|}{ Advanced glycosylation end-product (units/ml) } \\
\hline Baseline (0 month) & $2.39 \pm 0.15$ & $2.10 \pm 0.22$ & $2.34 \pm 0.22$ & $2.73 \pm 0.26$ \\
\hline 3 months & $2.01 \pm 0.18$ & $2.38 \pm 0.21$ & $2.30 \pm 0.26$ & $2.24 \pm 0.35$ \\
\hline 6 months & $2.12 \pm 0.22$ & $2.02 \pm 0.17$ & $1.98 \pm 0.25$ & $1.71 \pm 0.24^{*}$ \\
\hline \multicolumn{5}{|c|}{ Malondialdehyde (nmol/ml) } \\
\hline Baseline (0 month) & $4.25 \pm 0.30$ & $3.45 \pm 0.37$ & $4.18 \pm 0.23$ & $4.71 \pm 0.41$ \\
\hline 3 months & $4.82 \pm 0.34$ & $3.95 \pm 0.39$ & $3.22 \pm 0.22$ & $3.86 \pm 0.34$ \\
\hline 6 months & $3.95 \pm 0.31$ & $4.48 \pm 0.27$ & $3.87 \pm 0.36$ & $3.87 \pm 0.32$ \\
\hline
\end{tabular}

Values are expressed as mean \pm SEM.

Symbols indicate significant difference from baseline ( 0 month).

*: $p<0.05,{ }^{* *}: p<0.001$

by taking into account the tocotrienol-rich composition in the TRF, such a slow but steady increment is reasonable.

The tocotrienols are found in a wide variety of foods and it has been suggested recently that all 8 isomers of vitamin E may be necessary for optimum health [24]. This requirement maybe more crucial for the older individuals where digestion and absorption may not be as efficient resulting in the potential benefits of supplementation. Differences noted in the plasma levels of tocotrienols detected in various human studies are mainly

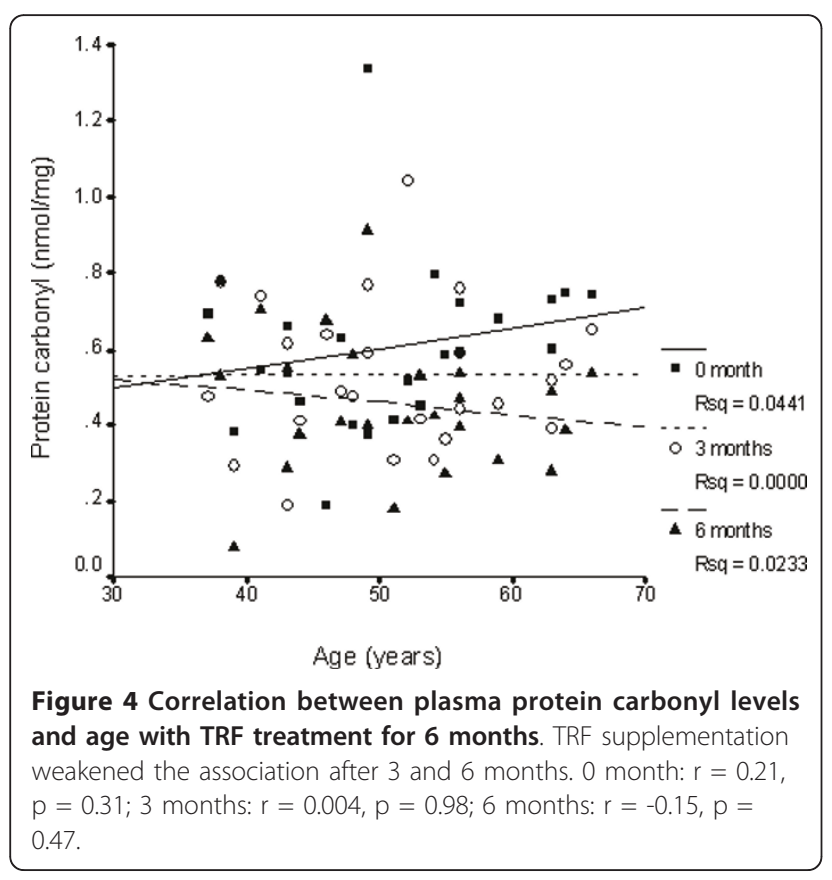

due to the different daily fat diet. Asians consume higher levels of palm oil rich in tocotrienols. Therefore, a comparatively higher absorption of tocotrienol and thus better level found in circulation.

The elevated plasma vitamin $C$ level detected in the present study was most likely absorbed from the diet, as the supplement is not a source of vitamin C. Indeed, we found a positive correlation between vitamin $C$ intake and plasma vitamin $C$ levels $(r=0.308, p=0.048)$. This is in accordance with findings by Padayatty et al. [57] who had reported that small changes in oral intake of

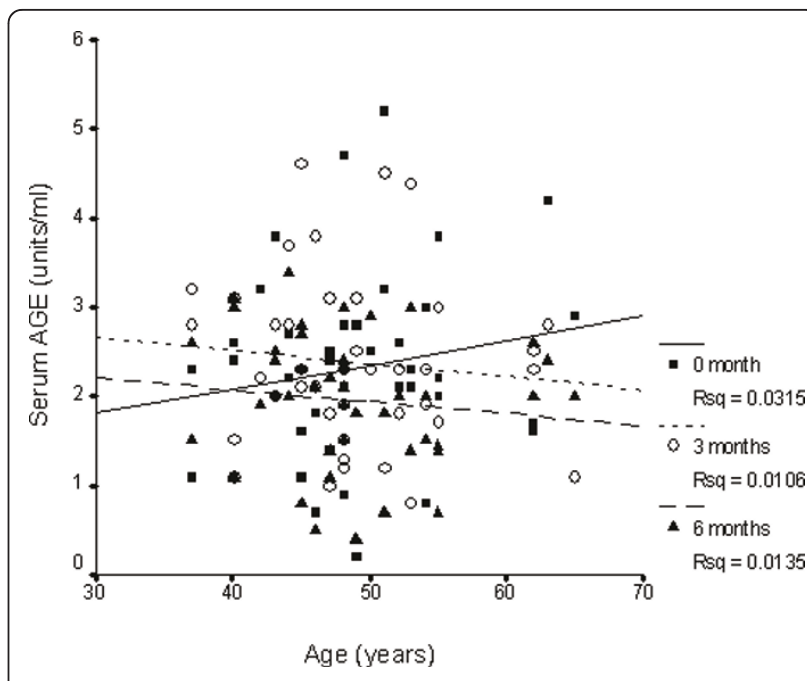

Figure 5 Correlation between serum advanced glycosylation end-products and age with TRF treatment for 6 months. TRF supplementation reversed the association after 3 and 6 months. 0 month: $r=0.18, p=0.21 ; 3$ months: $r=-0.13, p=0.37 ; 6$ months: $r$ $=-0.12, p=0.47$. 


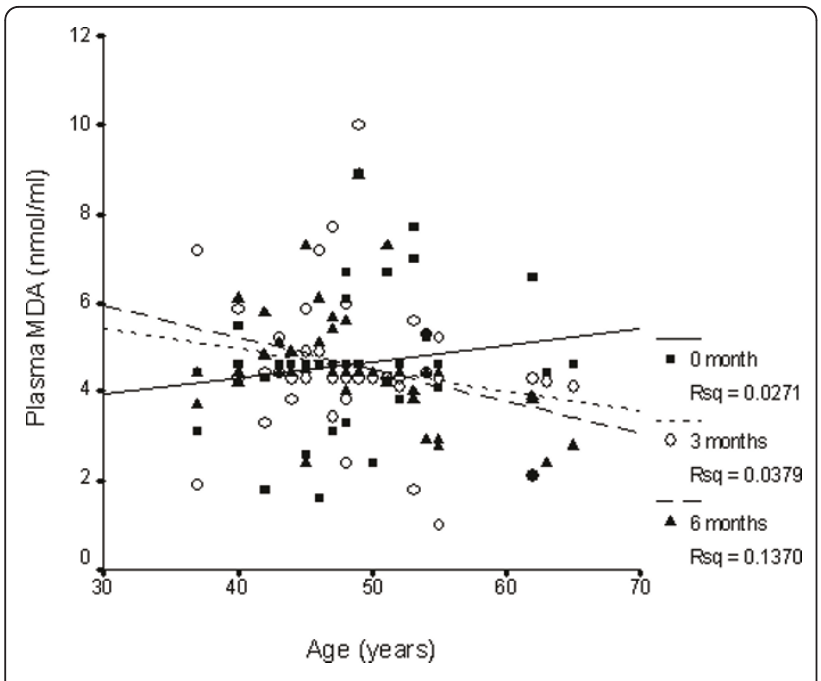

Figure 6 Correlation between plasma malondialdehyde levels and age with TRF treatment for 6 months. TRF supplementation reversed the association after 3 and 6 months. 0 month: $r=0.17, p$ $=0.25 ; 3$ months: $r=-0.19, p=0.22 ; 6$ months: $r=-0.37, p=0.02$.

vitamin $C$ resulted in large changes in plasma vitamin $C$ concentration. The increase in plasma vitamin $\mathrm{C}$ might also result from a complementary effect by vitamin $\mathrm{E}$ in an interlinking antioxidant network. The involvement of vitamin $\mathrm{C}$ in regenerating vitamin $\mathrm{E}$ directly from its tocotrienoxyl or tocopheroxyl radical back to tocotrienol and tocopherol respectively has been well documented [58]. Increased levels of vitamin $\mathrm{E}$ might reflect increased reactions with reactive free radicals, additional formation of tocotrienoxyl or tocopheroxyl radical, and a further increased need for vitamin $\mathrm{C}$.

The variation observed in enzyme activity might have been due to the different roles of the analysed antioxidant enzymes. The functional roles of these enzymes are well established, with SOD acting upstream by dismutating reactive superoxide anion radicals into more stable hydrogen peroxide $\left(\mathrm{H}_{2} \mathrm{O}_{2}\right)$ whereas catalase and GPx function downstream by converting $\mathrm{H}_{2} \mathrm{O}_{2}$ into water and oxygen in apparently parallel pathways. Changes in antioxidant enzymes activity observed were clearly in favour of the $>50$ years old group. Reduction in SOD activity with TRF supplementation after 3 and 6 months in the older group possibly due to lesser formation of radicals as a result of radical scavenging effect by tocotrienol and tocopherol. On the other hand, increase in GPx activity in both placebo and TRF group after 6 months possibly due to higher need for $\mathrm{H}_{2} \mathrm{O}_{2}$ removal. Increased level of tocotrienol and tocopherol attained by TRF supplementation might reflect more radical scavenging activity, followed by increased $\mathrm{H}_{2} \mathrm{O}_{2}$ formation and therefore increased requirement for its removal. As for the placebo group, increased intake of dietary vitamin $C$ might results in a similar increase in radical scavenging activity and the subsequent reactions involving formation and detoxification of $\mathrm{H}_{2} \mathrm{O}_{2}$. Given a decline in the catalase activity in the placebo group, the action of removing $\mathrm{H}_{2} \mathrm{O}_{2}$ was predominantly done by GPx. In the current study, the enzymes activity measured was evidently influenced by TRF supplementation as shown by the shifted correlation patterns with age.

Long term supplementation of TRF for 6 months caused the increase in plasma vitamin $\mathrm{E}$ availability (both tocopherol and tocotrienol) observed in the current study, accompanied by changes in the oxidative stress biomarkers measured. Protein carbonyls have been described as oxidized amino acids resulting from direct oxidation of protein by reactive oxygen species [59]. Proteins are also modified indirectly by glycation or glycoxidation of amino groups with the eventual formation of the advanced glycosylation end products (AGEs) [60]. Consistent with the fall in plasma concentrations of carbonylated protein with TRF supplementation, a sharp decrease in serum AGE was observed. When the effect of age was factored out of the statistical model, it was found that the interaction between supplementation and duration was significant for the older individuals, indicating a favourable gain in the older group. Figures 4, 5 and 6 give individual presentations of the changes in these oxidative markers with age. Ascending trends of protein damage and lipid peroxidation accumulation during ageing as shown by the correlative data were reduced, even reversed by TRF supplementation. These findings confirm that nutritional intervention can exert cumulative effects on oxidative stress in healthy individuals in the long term [27]. The unique combination of vitamin $\mathrm{E}$ isomers used in the study might have acted synergistically to provide the beneficial effect.

The reduced levels of oxidative markers were mainly observed in the older group, for whom the lower cut-off point was 50 years of age. This is of interest as previous studies typically evaluated older subjects, mostly 60 years old and over. It is also noteworthy that in the present study the treatment was administered to healthy individuals for a lengthy period of 6 months and studies involving supplementation of this duration are fairly limited. This may then results in the observed changes in oxidative status as measured by protein carbonyl and AGE. Although some of the younger subjects in the study also showed increased levels of antioxidant vitamins, the magnitude of changes was less evident as compared to the older individuals. The absence or lack of response by the younger age group might reflect a well-maintained antioxidant level, more effective maintenance of oxidative balance, and better defence against spontaneous oxidative injury. It is thus possible that 
TRF supplementation did not provide any further improvement. Although baseline antioxidant levels in the $>50$ year-old group were similar to those in the < 50 year-old group, baseline oxidative marker levels were higher in the older group, suggesting a higher level of oxidative damage. However, the amount of damaged lipids and proteins in this group was reduced by supplementation, probably due to the increased requirement for antioxidants in older individuals. It is possible that an antioxidant threshold for optimum performance exists and that this threshold (and therefore the requirement for antioxidants) could increase with ageing, thus allowing supplementation to generate an effect in the present study. A long-term prospective study will be required to test this hypothesis, particularly at the molecular level.

Compelling evidence suggests a new level of action for vitamin $\mathrm{E}$ under the non-antioxidative control in protection against disease [50]. Therefore, TRF might not only act directly or solely as an antioxidant, but it may actually also act through signalling pathways and specific signalregulated protein reaction as suggested by Sen et al. $[14,61]$. Tocotrienol was shown to provide complete neuroprotection via antioxidant-independent mechanism with the protective property reported not only limited in response to non-oxidative challenges but also to oxidative insults $[14,15]$. Further studies of the effects of tocotrienols in a cell model are currently underway in our laboratory.

\section{Conclusion}

Our data revealed an age-related increase in oxidative damage. We established a role of nutritional supplementation in oxidative damage and antioxidant levels in older individuals. To our best knowledge, tocotrienolrich vitamin $\mathrm{E}$ supplementation has not yet been studied in relation to oxidative stress in healthy older individuals. Consistent with increased concentrations of plasma antioxidants (vitamins $\mathrm{E}$ and $\mathrm{C}$ ), we observed significant decreases in protein carbonyl and AGE levels, as well as improvement of plasma cholesterol levels. The protective effects of TRF supplementation observed in this study might represent a restoration of redox balance, particularly in the $>50$-year old group. Increased tocotrienol level might be an important mechanism by which TRF supplementation confers its protective benefits via protection against oxidative stress, involvement in oxidized protein repair, besides contributing to the regulation of redox homeostasis through signalling.

\section{Acknowledgements}

The authors thank Ms. Zalina Hamid from Sime Darby Bioganic Sdn. Bhd. (Selangor, Malaysia) for supplying the TRF and placebo capsules used in the study, and Dr. Wan Nazaimoon Wan Mohamud (Division of Endocrinology, Institute for Medical Research, Kuala Lumpur, Malaysia) for kindly providing us with techniques and antibodies to measure the serum AGE concentration. Financial support for this study was provided by grants awarded from the Malaysian Government, the IRPA 06-02-02-0016-PR0008/ 09 and UKM-GUP-SK-07-21-199.

\section{Author details}

${ }^{1}$ Department of Biochemistry, Faculty of Medicine, Universiti Kebangsaan Malaysia, Kuala Lumpur, Malaysia. ${ }^{2}$ Department of Anatomy, Faculty of Medicine, Universiti Kebangsaan Malaysia, Kuala Lumpur, Malaysia. ${ }^{3}$ Department of Physiology, Faculty of Medicine, Universiti Kebangsaan Malaysia, Kuala Lumpur, Malaysia.

\section{Authors' contributions}

SFC was involved in the acquisition, analysis and interpretation of data in addition to drafting the manuscript; J, NAAH, AAL, ZZ and AAK made significant contributions to the acquisition of the data, SM was involved in interpretation of data and critical analysis of intellectual content of the manuscript, MM and YAMY contributed to the design, acquisition and interpretation of the data; and WZWN was instrumental in the study's inception, design and approval while providing critical analysis of data interpretation and manuscript review. The final manuscript have been read and approved by all authors.

\section{Competing interests}

The authors declare that they have no competing interests.

Received: 22 February 2011 Accepted: 24 June 2011

Published: 24 June 2011

\section{References}

1. Shay JW, Wright WE: Telomerase therapeutics for cancer: challenges and new directions. Nat Rev Drug Discov 2006, 5(7):577-584.

2. Yap WN, Chang PN, Han HY, Lee DTW, Ling MT, Wong YC, Yap YL: YTocotrienol suppresses prostate cancer cell proliferation and invasion through multiple-signalling pathways. British Journal of Cancer 2008, 99(11):1832-1841.

3. Meydani M: Vitamin E modulation of cardiovascular disease. Ann NY Acad Sci 2004, 1031:271-279.

4. Koga T, Kwan P, Zubik L, Ameho C, Smith D, Meydani M: Vitamin E supplementation suppresses macrophage accumulation and endothelial cell expression of adhesion molecules in the aorta of hypercholesterolemic rabbits. Atherosclerosis 2004, 176(2):265-272.

5. Montiel T, Quiroz-Baez R, Massieu L, Arias C: Role of oxidative stress on beta-amyloid neurotoxicity elicited during impairment of energy metabolism in the hippocampus: protection by antioxidants. Exp Neurol 2006, 200:496-508.

6. Butterfield DA, Castegna A, Drake J, Scapagnini G, Calabrese V: Vitamin E and neurodegenerative disorders associated with oxidative stress. Nutr Neurosci 2002, 5:229-239.

7. Inokuchi H, Hirokane H, Tsuzuki T, Nakagawa K, Igarashi M, Miyazawa T: Antiangiogenic activity of tocotrienol. Biosci Biotechnol Biochem 2003, 67(7):1623-1627

8. Mizushina Y, Nakagawa K, Shibata A, Awata Y, Kuriyama I, Shimazaki N, Koiwai O, Uchiyama Y, Sakaguchi K, Miyazawa T, Yoshida H: Inhibitory effect of tocotrienol on eukaryotic DNA polymerase lambda and angiogenesis. Biochem Biophys Res Commun 2006, 339(3):949-955.

9. Nesaretnam K, Dorasamy S, Darbre PD: Tocotrienols inhibit growth of ZR75-1 breast cancer cells. Int J Food Sci Nutr 2000, , Suppl 51: S95-S103.

10. Khor HT, Ng TT: Effects of administration of alpha-tocopherol and tocotrienols on serum lipids and liver HMG CoA reductase activity. Int J Food Sci Nutr 2000, , Suppl 51: S3-S11.

11. Qureshi AA, Qureshi N, Wright JJ, Shen Z, Kramer G, Gapor A, Chong YH, DeWitt G, Ong A, Peterson DM: Lowering of serum cholesterol in hypercholesterolemic humans by tocotrienols (palmvitee). Am J Clin Nutr 1991, 53(Suppl 4):1021S-1026S.

12. Qureshi AA, Bradlow BA, Brace L, Manganello J, Peterson DM, Pearce BC, Wright JJ, Gapor A, Elson CE: Response of hypercholesterolemic subjects to administration of tocotrienols. Lipids 1995, 30(12):1171-1177.

13. Qureshi AA, Sami SA, Salser WA, Khan FA: Dose-dependent suppression of serum cholesterol by tocotrienol-rich fraction (TRF25) of rice bran in hypercholesterolemic humans. Atherosclerosis 2002, 161(1):199-207. 
14. Sen CK, Khanna S, Roy S, Packer L: Molecular basis of vitamin E action. Tocotrienol potently inhibits glutamate-induced pp60(c-Src) kinase activation and death of HT4 neuronal cells. J Biol Chem 2000, 275(17):13049-13055.

15. Khanna S, Roy S, Parinandi NL, Maurer M, Sen CK: Characterization of the potent neuroprotective properties of the natural vitamin $E$ alphatocotrienol. J Neurochem 2006, 98(5):1474-1486.

16. Halliwell B: Role of free radicals in the neurodegenerative diseases: therapeutic implications for antioxidant treatment. Drugs Aging 2001, 18:685-716.

17. Holliday R: Aging is no longer an unsolved problem in biology. Ann NY Acad Sci 2006, 1067:1-9.

18. Duthie SJ, Ma A, Ross MA, Collins AR: Antioxidant supplementation decreases oxidative DNA damage in human lymphocytes. Cancer Res 1996, 56(6):1291-1295.

19. Lee BM, Lee SK, Kim HS: Inhibition of oxidative DNA damage, 8-OHdG and carbonyl contents in smokers treated with antioxidants (vitamin $E_{\text {, }}$ vitamin C, beta-carotene and red ginseng). Cancer Lett 1998, 132(1/ 2):219-227.

20. Jenkinson AM, Collins AR, Duthie SJ, Wahle KW, Duthie GG: The effect of increased intakes of polyunsaturated fatty acids and vitamin E on DNA damage in human lymphocytes. FASEB J 1999, 13(15):2138-2142.

21. Dereska NH, McLemore EC, Tessier DJ, Bash DS, Brophy CM: Short-term, moderate dosage vitamin E supplementation may have no effect on platelet aggregation, coagulation profile and bleeding time in healthy individuals. J Surg Res 2006, 132:121-129.

22. The HOPE Study Investigators: Vitamin E supplementation and cardiovascular events in high-risk patients. N Engl J Med 2000, 342:154-160

23. Rapola JM, Virtamo J, Haukka JK, Heinonen OP, Albanes D, Taylor PR, Huttunen JK: Effect of vitamin $\mathrm{E}$ and beta carotene on the incidence of angina pectoris: A randomized, double-blind, controlled trial. JAMA 1996, 275:693-698.

24. Krishnan K, Stone W, Campbell S: More optimal forms of vitamin E. Letters to the editor. J Am Diet Assoc 2005, 105(2):204-205.

25. Winklhofer-Roob BM, Roob JM, Maritschnegg M, Sprinz G, Hiller D, Marktfelder E, Preinsberger M, Wuga S, Sundl I, Tiran B, Cardinault N, Ribalta J, Rock E, Vitage Study Group: Does aging affect the response of vitamin E status to vitamin E depletion and supplementation? Ann NY Acad Sci 2004, 1031:381-384.

26. Andriollo-Sanchez M, Hininger-Favier I, Meunier N, Venneria E, O'Connor JM, Maiani G, Coudray C, Roussel AM: Age-related oxidative stress and antioxidant parameters in middle-aged and older European subjects: the ZENITH study. Eur J Clin Nutr 2005, 59(Suppl 2):S58-S62.

27. Chin SF, Noor Aini AH, Azian AL, Zaiton Z, Musalmah M, Yasmin AMY, Aminuddin AK, Johari I, Zalina $\mathrm{H}$, Wan Zurinah WN: Reduction of DNA damage in older healthy adults by Tri ${ }^{\circledR}{ }^{\circledR}$ Tocotrienol supplementation. Nutrition 2008, 24:1-10.

28. Mastaloudis A, Leonard SW, Traber MJ: Oxidative stress in athletes during extreme endurance exercise. Free Radic Biol Med 2001, 31(7):911-922.

29. O'Byrne D, Grundy S, Packer L, Devaraj S, Baldenius K, Hoppe PP, Kraemer K, Jialal I, Traber MG: Studies of LDL oxidation following $\alpha^{-}, \gamma^{-}$, or $\delta$ tocotrienyl acetate supplementation of hypercholesterolemic humans. Free Radic Biol Med 2000, 29(9):834-845.

30. Pachla LA, Kissinger PT: Analysis of ascorbate by liquid chromatography with amperometric detection. Methods Enzymol 1979, 62:15-24.

31. Levine RL, Williams JA, Stadtman EP, Shacter E: Carbonyl assays for determination of oxidatively modified proteins. Methods Enzymol 1994, 233:346-357.

32. Wan Nazaimoon WM, Khalid BAK: An enzyme immunoassay for advanced glycosylation end-products in serum. Malaysian J Pathol 1998, 20(2):83-89.

33. Pilz J, Meineke I, Gleiter CH: Measurement of free and bound malondialdehyde in plasma by high-performance liquid chromatography as the 2, 4-dinitrophenylhydrazine derivative. J Chrom B 2000, 742:315-325

34. Beyer WF Jr, Fridovich I: Assaying for superoxide dismutase activity: some large consequences of minor changes in conditions. Anal Biochem 1987, 161(2):559-566.

35. Aebi H: Catalase in vitro. Methods Enzymol 1984, 105:121-126.
36. Paglia DE, Valentine WN: Studies on the quantitative and qualitative characterization of erythrocyte glutathione peroxidase. J Clin Med 1967, 70:158-169.

37. Papet I, Dardevet D, Sornet C, Béchereau F, Prugnaud J, Pouyet C, Obled C: Acute phase protein levels and thymus, spleen and plasma protein synthesis rates differ in adult and old rats. J Nutr 2003, 133:215-219.

38. Pletcher SD, Libert S, Skorupa D: Flies and their golden apples: The effect of dietary restriction on Drosophila aging and age-dependent gene expression. Ageing Res Rev 2005, 4:451-480.

39. Friel JK, Widness JA, Jiang T, Belkhode SL, Rebouche CJ, Ziegler EE: Antioxidant status and oxidant stress may be associated with vitamin $E$ intakes in very low birth weight infants during the first month of life. Nutr Res 2002, 22:55-64.

40. Natarajan S, Glick H, Criqui M, Horowitz D, Lipsitz SR, Kinosian B: Cholesterol measures to identify and treat individuals at risk for coronary heart disease. Am J Prev Med 2003, 25:50-57.

41. Shai I, Rimm EB, Hankinson SE, Curhan G, Manson JAE, Rifai N, Stampfer MJ, Ma J: Multivariate assessment of lipid parameters as predictors of coronary heart disease among postmenopausal women: Potential implications for clinical guidelines. Circulation 2004, 110:2824-2830.

42. Haffner S: Rationale for new American Diabetes Association Guidelines: are national cholesterol education program goals adequate for the patient with Diabetes Mellitus? Am J Cardiol 2005, 96(4A):33E-36E.

43. da Costa VAV, Vianna LM: Effect of a -tocopherol supplementation on blood pressure and lipidic profile in streptozotocin-induced diabetes mellitus in spontaneously hypertensive rats. Clin Chim Acta 2005, 351:101-104.

44. Komaratat $P$, Chupukcharoen N, Wilairat P: Effect of vitamin $E$ on cholesterol plasma lipoprotein distribution and metabolism in rabbit. Int J Vitam Nutr Res 1985, 55:167-171.

45. Hermann WJ Jr, Ward K, Faucett J: The effect of tocopherol on highdensity lipoprotein cholesterol. A clinical observation. Am J Clin Pathol 1979, 72:848-852.

46. van Tits $L H$, de Waart F, Hak-Lemmers HLM, van Heijst P, de Graaf J, Demacker PNM, Stalenhoef AFH: Effects of a -tocopherol on superoxide production and plasma intercellular adhesion molecule- 1 and antibodies to oxidized LDL in chronic smokers. Free Radic Biol Med 2001, 30(10):1122-1129.

47. Perugini C, Bagnati M, Cau C, Bordone R, Paffoni P, Re R, Zoppis E, Albano E, Bellomo G: Distribution of lipid-soluble antioxidants in lipoproteins from healthy subjects. II. Effects of in vivo supplementation with a-tocopherol. Pharmacol Res 2000, 41(1):67-74.

48. Packer L, Weber SU, Rimbach G: Molecular aspects of a-tocotrienol antioxidant action and cell signalling. J Nutr 2001, 3695-373S.

49. Qureshi AA, Sami SA, Salser WA, Khan FA: Dose-dependent suppression of serum cholesterol by tocotrienol-rich fraction $\left(\mathrm{TRF}_{25}\right)$ of rice bran in hypercholesterolemic humans. Atherosclerosis 2002, 161:199-207.

50. Azzi A, Gysin R, Kempna P, Ricciarelli R, Villacorta L, Visarius T, Zingg JM: Regulation of gene and protein expression by Vitamin E. Free Radic Res 2002, 36(1):30-35.

51. Nicklas BJ, Katzel LI, Busby-Whitehead J, Goldberg AP: Increases in highdensity lipoprotein cholesterol with endurance exercise training are blunted in obese compared with lean men. Metabolism 1997, 46(5):556-561.

52. Delgado M, González-Gross M, Cano MD, Gutiérrez A, Castillo MJ: Physical exercise reverses diet-induced increases in LDL-cholesterol and apo B levels in healthy ovo-lactovegetarian subjects. Nutr Res 2000, 20(12):1707-1714.

53. Sen CK, Khanna S, Roy S: Tocotrienols in health and disease: the other half of the natural vitamin E family. Mol Aspects Med 2007, 28:692-728.

54. Hoppe PP, Krennrich G: Bioavailability and potency of natural-source and all-racemic alpha-tocopherol in the human: a dispute. Eur J Nutr 2000, 39:183-193.

55. Burton GW, Traber MG, Acuff RV, Walters DN, Kayden H, Hughes L, Ingold KU: Human plasma and tissue alphatocopherol concentrations in response to supplementation with deuterated natural and synthetic vitamin E. Am J Clin Nutr 1998, 67:669-684.

56. Lodge JK: Vitamin E bioavailability in humans. J Plant Physiol 2005 162:790-796. 
57. Padayatty SJ, Katz A, Wang Y, Eck P, Kwon O, Lee JH, Chen S, Corpe C, Dutta A, Dutta SK, Levine M: Vitamin C as an antioxidant: Evaluation of its role in disease prevention. J Am Coll Nutr 2003, 22(1):18-35.

58. Neuzil J, Thomas SR, Stocker R: Requirement for promotion or inhibition by alpha-tocopherol of radical-induced initiation of plasma lipoprotein lipid peroxidation. Free Radic Biol Med 1997, 22:57-71.

59. Stadtman ER, Levine RL: Protein oxidation. Ann NY Acad Sci 2000 899:191-208.

60. Inagi R, Miyata T: Oxidative protein damage with carbohydrates and lipids in uremia: 'Carbonyl stress'. Blood Purif 1999, 17:95-98.

61. 61 Sen CK, Khanna S, Roy S: Tocotrienol: the natural vitamin E to defend the nervous system? Ann NY Acad Sci 2004, 1031:127-142.

doi:10.1186/1743-7075-8-42

Cite this article as: Chin et al: Tocotrienol rich fraction supplementation improved lipid profile and oxidative status in healthy older adults: A randomized controlled study. Nutrition \& Metabolism 2011 8:42.

\section{Submit your next manuscript to BioMed Central} and take full advantage of:

- Convenient online submission

- Thorough peer review

- No space constraints or color figure charges

- Immediate publication on acceptance

- Inclusion in PubMed, CAS, Scopus and Google Scholar

- Research which is freely available for redistribution

Submit your manuscript at www.biomedcentral.com/submit
Ciomed Central 